\title{
La dudosa constitucionalidad de la regulación legal de las medidas limitativas de derechos fundamentales del deudor en el proceso concursal
}

\author{
Manuel Díaz Martínez \\ Profesor Titular de Derecho Procesal \\ Universidad Nacional de Educación a Distancia
}

Recibido: 21.07.2011

Aceptado: 02.11.2011

\begin{abstract}
Resumen: La Regulación contenida en la LO 8/2003, de 9 de julio, para la reforma concursal supone una mejora notable en relación con la establecida en la LEC de 1881 y el C.Com. de 1829, toda vez que no sólo unifica en un texto legal la normativa anterior, sino que además establece como único objetivo asegurar el cumplimiento de los fines del concurso, suprimiendo el efecto automático y represivo que presentaban tales medidas en la normativa anterior. Sin embargo, la misma presenta en aspectos esenciales vaguedad e indeterminación, lo cual que hace que los requisitos de certeza y seguridad, no se hallen en ocasiones cumplidos, lo que genera serias dudas en cuanto a su constitucionalidad.
\end{abstract}

Palabras claves: Derecho concursal, constitucionalidad, derecho mercantil, deudor, juez de lo mercantil, código de comercio, principio de legalidad, principio de proporcionalidad.

Abstract: The Regulation contained in the LO 8/2003, 9 July, for the bankruptcy reform supposes a relevant improvement in relation to the LEC of 1881 and the Code of Commerce of 1829, because it unifies in a legal text the other law,but it also establishes as a unique goal the accomplishment of the purpose of the bankruptcy process, abolishing the automatic and repressive effects that the former laws had. However, the LO 8/2003, 9 July, for bankruptcy reform, has in its essential aspects vagueness and inaccuracies, which makes the requirements of certainty and security unfulfilled, which results in serious doubts regarding its constitutionality.

Key words: Bankruptcy Law, constitutionality, commercial law, debtor, commercial judge, commercial code, principle of legality, principle of proportionality.

SUMARIO. I. Concepto, regulación legal y naturaleza. II. Presupuestos exigibles para la adopción de medidas limitativas de derechos fundamentales del concursado. 1. Principio de legalidad. 2. Principio de jurisdiccionalidad. 3. Principio de proporcionalidad. 4. Duración de la medida. III. Intervención de las comunicaciones. IV. La entrada y registro en el domicilio del deudor. V. La obligación de residencia y el arresto domiciliario. VI. Aspectos procesales. 1. Momento procesal para su adopción. 2. Legitimación. 3. Procedimiento y recursos. VII. Conclusiones. 


\section{CONCEPTO, REGULACIÓN LEGAL Y NATURALEZA}

La LC 22/2003 ha dado un paso importante en aras de la efectividad del proceso concursal y de su normal tramitación: de un lado, estableciendo la obligación del deudor de colaborar activamente en todo lo necesario o conveniente para el interés del concurso y, de otro, permitiendo al Juez de lo Mercantil acordar la intervención de las comunicaciones, la imposición del deber de residencia y la entrada en el domicilio del deudor, tanto en los supuestos de suspensión como en los de intervención en el ejercicio de las facultades patrimoniales del concursado.

En efecto, de manera similar a lo que acontece en el proceso civil (art. 591 LEC), el art. 42 LC establece un deber amplio de colaboración del deudor en el proceso concursal, que se concreta en la obligación de comparecencia ante el Juzgado de lo Mercantil y la administración concursal cuantas veces sea requerido, con la finalidad de colaborar e informar en todo lo necesario o conveniente para el interés del concurso, especialmente aportando cuantos documentos y datos tengan relación con el objeto del proceso.

Junto a este deber de colaboración, la LO 8/2003, de 9 de julio, para la reforma concursal (LORC, en lo sucesivo) contempla en su articulo primero («efectos del concurso sobre derechos fundamentales del concursado») la posibilidad de que el Juez Mercantil pueda adoptar una serie de medidas que, como nota esencial a todas ellas, restringen determinados derechos fundamentales de la persona del deudor ${ }^{1}$, como lo son los de libertad, secreto de las comunicaciones, inviolabilidad del domicilio y libre residencia y circulación por el territorio nacional (arts. 17, 18 y $19 \mathrm{CE})^{2}$.

${ }^{1}$ El TEDH ha entendido que las medidas restrictivas de derechos fundamentales en los procesos concursales sirven a un fin legítimo. Así, las Sentencias de este Tribunal dictadas en los casos Luordo contra Italia y Bottaro contra Italia, ambas de de 17 de julio de 2003, disponen que la intervención de la correspondencia en un proceso de quiebra (y el argumento puede aplicarse asimismo a la intervención de las comunicaciones telefónicas y a la entrada y registro, que tienen la misma naturaleza de medidas de investigación del patrimonio del concursado), dirigida a obtener los datos necesarios sobre la situación patrimonial del quebrado, con el fin de que éste no ponga sus bienes fuera del alcance de sus acreedores, responde a un fin legítimo en el sentido del art. 8.2 del Convenio, como es el de proteger los derechos de los demás, en este caso, de los acreedores. Y estas mismas sentencias del TEDH, consideran que la limitación del derecho a la libertad de circulación del quebrado, consistente en la prohibición de alejarse de su lugar de residencia, con el objetivo de garantizar que se pueda mantener el contacto con él para facilitar el desarrollo del procedimiento, responde asimismo a un fin legítimo en el sentido del artículo 2 del Protocolo número 4 del Convenio.

${ }^{2}$ Conviene señalar que, si bien el artículo primero de la LORC regula, exclusivamente, las medidas que pueden suponer una injerencia en los mencionados derechos constitucionales, razón por la cual se incorporan a un texto con rango orgánico de conformidad con lo dispuesto en el art. $81 \mathrm{CE}$, nada impide que, a lo largo del proceso concursal, puedan adoptarse las medidas cautelares previstas en la LEC, habida cuenta de su aplicación supletoria a dicho proceso (D.F. $5^{\text {a }}$ LC). 
Dicha regulación supone una mejora en relación con la contenida en la LEC de 1881 y el C.Com. de 1829, ya que no sólo supone una unificación en un mismo texto legal de la dispersa normativa anterior, sino que también desaparece su carácter automático, teniendo una función no ya represiva, ni sancionadora, sino asegurativa del cumplimiento de las finalidades del proceso concursal, tal y como afirma su Exposición de Motivos ${ }^{3}$.

Por desgracia, este es el único aspecto positivo que cabe destacar, ya que la regulación contenida en dicho artículo primero presenta numerosas deficiencias y omisiones, que hacen dudar tanto de su constitucionalidad, cuanto de su eficacia práctica en relación con la finalidad que se pretende con la adopción de tales medidas limitadoras de derechos del concursado, que no es otra que la de facilitar el correcto desenvolvimiento del concurso como proceso orientado a la satisfacción de los acreedores.

Aun cuando la LORC las regula de modo conjunto, tales medidas limitativas de derechos fundamentales presentan una distinta finalidad: las que limitan el secreto de las comunicaciones o autorizan la entrada y registro domiciliario están dirigidas a la obtención de información y documentos que sean relevantes a los fines del concurso, mientras que las que establecen un concreto deber de residencia o el arresto domiciliario irán encaminadas al aseguramiento de la presencia del deudor y, en consecuencia, su adopción se supedita a la existencia de un «peligro de fuga» o de ocultación personal del deudor al proceso concursal ${ }^{4}$.

En cuanto a la naturaleza de tales medidas, no cabe duda alguna que nos encontramos ante medidas civiles que se adoptan en el marco de un procedimiento de ejecución universal y que tienen un fundamento distinto a las mismas medidas acordadas por un Juez de Instrucción, si bien, los silencios del legislador, la intervención preceptiva del MF, así como la remisión expresa que se efectúa a la LECrim en relación con medidas como la intervención de comunicaciones telefónicas, pudieran dar la impresión que se está colocando al Juez de lo Mercantil en el papel de un Juez Instructor, cuando su labor es radicalmente distinta.

\footnotetext{
${ }^{3}$ La Exposición de Motivos de la LORC dispone: «La reforma concursal ha de orientarse, conforme a la doctrina del Tribunal Constitucional, en el sentido de atemperar el rigor de esos efectos, suprimir aquellos de carácter represivo y limitarse a establecer los necesarios desde un punto de vista funcional, en beneficio de la tramitación normal del procedimiento y en la medida en que ésta lo exija, confiriendo al Juez la potestad de graduarlos y de adecuarlos a las circunstancias concretas de cada caso; pero es inevitable que en algunos de estos supuestos esos efectos alcancen a derechos fundamentales de la persona del deudor, como son los de la libertad, el secreto de las comunicaciones, inviolabilidad del domicilo y libre residencia y circulación por el territorio nacional».

${ }^{4}$ En este sentido, Vid. ASENCIO MELLADO, J.M., Ley Concursal (AA.VV., Coordinadora: Esperanza Gallego Sánchez), Tomo I, La Ley, 2002, pág. 505.
} 


\section{PRESUPUESTOS EXIGIBLES PARA LA ADOPCIÓN DE MEDI- DAS LIMITATIVAS DE DERECHOS FUNDAMENTALES DEL CONCURSADO}

Debido a la circunstancia de que las medidas contempladas en el artículo primero de la LORC restringen derechos fundamentales del concursado, tales actos procesales requieren, como presupuesto inicial y genérico, que se encuentren previstos por Ley (principio de legalidad) y la intervención de un órgano jurisdiccional en la adopción de la injerencia (principio de jurisdiccionalidad), así como la estricta observancia del principio de proporcionalidad, concretado en tres requisitos o condiciones: idoneidad de la medida, necesidad de la misma y proporcionalidad en sentido estricto ${ }^{5}$.

\section{Principio de legalidad}

Un presupuesto común para todo acto limitativo de algún derecho fundamental lo constituye el principio de legalidad, según el cual toda injerencia del poder público en los derechos fundamentales requiere que haya sido autorizada o habilitada por una disposición con rango de Ley ${ }^{6}$ y que la norma legal habilitadora de la injerencia reúna las condiciones mínimas suficientes requeridas por las exigencias de seguridad jurídica y certeza del Derecho, para aportar al individuo una protección adecuada contra la arbitrariedad ${ }^{7}$.

Desde la exigencia de que una norma legal habilite la injerencia, no ofrece duda alguna que la LO 8/2003 contiene tal habilitación.

Sin embargo, desde las exigencias de seguridad y certeza del Derecho, que también han de presidir cualquier injerencia en un derecho fundamental, dicho texto legal posee una dudosa legitimidad constitucional, habida cuenta que su artículo primero, como tendremos ocasión de comprobar, no está redactado con la claridad suficiente que permita al deudor conocer en

\footnotetext{
${ }^{5}$ Vid., por todas, STC 207/1996.

${ }^{6}$ Tal y como afirma la STC 49/1999, «esa reserva de Ley a que, con carácter general, somete la CE la regulación de los derechos fundamentales y libertades públicas, desempeña una doble función, a saber: de una parte, asegura que los derechos que la CE atribuye a los ciudadanos no se vean afectados por ninguna injerencia estatal no autorizada por sus representantes; $y$, de otra, en un ordenamiento jurídico como el nuestro, en el que los Jueces y Magistrados se hallan sometidos «únicamente al imperio de la Ley» y no existe, en puridad, la vinculación al precedente, constituye, en definitiva, el único modo efectivo de garantizar las exigencias de seguridad jurídica en el ámbito de los derechos fundamentales y las libertades públicas».

${ }^{7}$ Cfr. SSTEDH 24 de abril de 1990, caso Kruslin y Huvig; 30 de julio de 1998, caso Valenzuela; 20 de mayo de 1999, caso Rekvényi; 25 de noviembre de 1999, caso Hashman y Harrup; 16 de febrero de 2000, caso Amann; 4 de mayo de 2000, caso Rotaru.
} 
qué circunstancias y bajo qué condiciones se habilita al Juez del concurso a adoptar tales medidas ${ }^{8}$.

\section{Principio de jurisdiccionalidad}

El segundo presupuesto genérico que ha de observarse en la adopción de cualquier medida restrictiva de derechos fundamentales es el de jurisdiccionalidad, según el cual dichas medidas, como regla general, sólo pueden ser adoptadas por los órganos judiciales, por cuanto en este ámbito (el de la tutela de los derechos fundamentales) la jurisdicción ha de ostentar siempre «no sólo la última, sino la primera palabra».

En este punto, la LORC cumple de forma clara y terminante con dicho presupuesto, por cuanto la limitación de tales derechos sólo puede ser acordada por el Juez del concurso (artículo primero.1).

\section{Principio de proporcionalidad}

Junto al cumplimiento de los principios de legalidad y jurisdiccionalidad, la legitimidad constitucional de una medida limitativa de derechos fundamentales requiere el estricto cumplimiento del principio de proporcionalidad, que se concreta en la exigencia de tres requisitos, que brevemente expuestos son: a) La idoneidad de la medida o, lo que es lo mismo, que la medida sea adecuada y útil para la obtención del fin perseguido, lo que exige atender al estado del procedimiento de concurso; b) Su necesidad, lo que obliga al órgano judicial a examinar, no sólo la idoneidad de la medida, sino también si existe alguna otra alternativa menos gravosa que, asegurando el cumplimiento de los fines del concurso, ello no obstante, no supongan el sacrificio del derecho fundamental afectado; y c) Proporcionalidad en sentido estricto, que se aplica, una vez aceptada la idoneidad y necesidad de una medida, con el fin de determinar, mediante la utilización de las técnicas del contrapeso de bienes o valores y la ponderación de intereses según las circunstancias del caso concreto, si el sacrificio de los intereses individuales que comporta la injerencia guarda una relación razonable o proporcionada con la importancia del interés estatal que se trata de salvaguardar".

En relación con el requisito de que exista una adecuada proporción entre el alcance de la medida y el resultado u objetivo perseguido (proporcionalidad en sentido estricto), como criterio de legitimidad constitucional, resulta

${ }^{8}$ En este sentido. Vid. ASENCIO MELLADO, J.M ${ }^{\mathrm{a}}$., El problema de la constitucionalidad de las medidas limitativas de derechos del concursado, en Anuario de Derecho Concursal, 17/2009-2, pág. 262.

${ }^{9} \mathrm{Vid}$. GONZÁLEZ-CUELLAR SERRANO, N., Proporcionalidad y derechos fundamentales en el proceso penal, Editorial Colex, 1990, págs. 69 y ss. 
preciso atender a dos cuestiones esenciales, como medio de valorar tal proporcionalidad: la finalidad del proceso concursal y el cumplimiento o incumplimiento por el deudor de sus obligaciones concursales ${ }^{10}$.

En primer lugar, para que una medida restrictiva de derechos fundamentales del concursado sea proporcionada requiere que se ajuste a la finalidad del proceso concursal que, como es sabido, reside en la satisfacción de los acreedores a través de la continuación de la empresa, siempre y cuando sea viable.

Del mismo modo, la proporcionalidad de la medida debe estar fundada en el cumplimiento por el concursado de sus obligaciones y, en concreto, de su deber de colaboración e información con el Juez y la administración concursal en todo lo necesario o conveniente para el interés del concurso (art. 42 LC).

Ello supone que si, requerido el concursado, no aporta la documentación o la información solicitada sobre los acreedores, la situación contable de la empresa o su situación patrimonial o financiera, así como cuando se tengan indicios de que sustrae u oculta información relevante, estarán justificadas medidas tan restrictivas como lo son la entrada y registro de su domicilio o la intervención de sus comunicaciones, al igual que acontece en el proceso civil ante la negativa del futuro demandado de exhibición de documentos o títulos relevantes a los efectos de fundamentar la pretensión (art. 261 LEC).

Por último, como exigencia formal del principio de proporcional, se impone el deber constitucional de motivación de las resoluciones judiciales limitativas de derechos fundamentales, expresando en ellas las circunstancias que justifican tal limitación con la finalidad de hacer posible el debate y comprobación de la legalidad y racionalidad de la medida acordada. Para ello, el órgano judicial, en la resolución que adopte, debe efectuar necesariamente el juicio de ponderación entre el derecho o derechos fundamentales afectados y los intereses que tal afectación trata de proteger.

\section{Duración de la medida}

Una medida procesal restrictiva de derechos fundamentales, aun cuando resulte idónea o adecuada con el fin perseguido, puede ser intolerable en un Estado de Derecho si su duración e intensidad no son exigidas por la propia finalidad que pretenda alcanzar, cualquiera que sea el carácter del proceso y el fin de la medida.

Por ello, resulta necesario que la resolución judicial que acuerde la medida fije su duración, durante el tiempo estrictamente necesario para asegurar

${ }^{10}$ Cfr. CARRERAS MARAÑA, J.M., «Efectos del concurso sobre los derechos fundamentales del concursado. Análisis del artículo primero de la Ley Orgánica 8/2003, de 9 de julio», en Estudios de Derecho Judicial. Aspectos penales de la nueva Ley concursal, CGPJ, Núm. 54, 2004, págs. 289-292. 
el resultado u objetivo perseguido, que nunca podrá exceder de la fecha concreta establecida como plazo máximo, que ha de ser determinada por el Juez Mercantil, sin perjuicio de que pueda ser prorrogada con posterioridad, si persisten los motivos que justificaron su adopción. En tales términos debiera interpretarse la defectuosa redacción del artículo primero 3.d) cuando dispone que el Juez determinará la duración de la medida, con fijación del tiempo máximo de vigencia, que no podrá exceder del estrictamente necesario (...).

En todo caso, hubiera sido deseable que el propio legislador hubiera establecido unos plazos máximos de duración, al menos en relación con el arresto domiciliario, tal y como sucede en el proceso penal con la detención o prisión provisional.

\section{INTERVENCIÓN DE LAS COMUNICACIONES}

La primera de las medidas contempladas en el artículo primero de la LORC es la intervención de las comunicaciones del deudor, sin limitación a unas concretas comunicaciones, por lo que el objeto material, a través del cual puede restringirse el derecho fundamental al secreto de las comunicaciones del art. 18.3 de la CE, es cualquier medio de comunicación a través del cual se transmita una información privada, sea oral, postal, telegráfica, telefónica, incluidas las inalámbricas, radioléctrica o cibernética.

Una cuestión interesante que se plantea es la relativa a la relación existente entre los efectos del concurso en las facultades patrimoniales del deudor y la intervención de las comunicaciones, por cuanto la LORC no hace distinción alguna entre las comunicaciones de la empresa o centro de actividades y comunicaciones personales.

En mi opinión, la configuración constitucional del derecho que protege las comunicaciones con independencia de su contenido, la literalidad del precepto citado que hace alusión simplemente a las comunicaciones del deudor sin distinción alguna entre comunicaciones empresariales y comunicaciones personales y la ausencia de vinculación entre los efectos del concurso en las facultades patrimoniales del deudor y los efectos en sus derechos fundamentales, obligan a entender que, si se acuerda la suspensión de las facultades patrimoniales del deudor, los administradores concursales no podrán servirse de las comunicaciones que venían siendo empleadas por éste para el desempeño de su actividad, a menos que exista una resolución judicial acordando su intervención ${ }^{11}$.

Tratándose de la intervención de las comunicaciones telefónicas, el artículo primero, apartado 4 de la LORC, sorprendentemente efectúa una remisión en bloque a lo previsto en la LECrim., habiendo desaprovechado el

${ }^{11}$ En contra, MARTÍNEZ FLORES Y OLEO, en Comentarios a la Ley Concursal (dirigidos por Ángel ROJO y Emilio BELTRÁN), Editorial Thomson-Civitas, 2004, Tomo I, pg. 849. 
legislador la oportunidad que se le ofrecía de incorporar a nuestro derecho interno, en el ámbito específico del proceso concursal, la doctrina que tanto el TEDH, como el TC han elaborado a propósito de la intervención telefónica acordada judicialmente en el curso de un proceso penal.

Decimos que de forma sorprendente por cuanto el TEDH, en sus Sentencias de 18 de febrero de 2003 (Prado Bugallo c. España) y 30 de julio de 1998 (Caso Valenzuela Contreras c. España) ha declarado la vulneración del art. 8 CEDH debido a que el actual art. 579 LECrim. (precepto que regula las intervenciones telefónicas) no cumple con las exigencias relativas a la previsión legal de la injerencia, al omitir aspectos tan importantes como lo son la naturaleza de las infracciones susceptibles de dar lugar a las escuchas, la fijación de un límite a la duración de la ejecución de la medida, las condiciones de trascripción de las conversaciones interceptadas y las precauciones a adoptar para mantener intactas y completas las grabaciones realizadas, a los fines del eventual control por el Juez y la defensa.

Así pues, ha de partirse de la insuficiente regulación legal establecida en el art. 579 LECrim. y, en consecuencia, del artículo primero, apartado 4 de la LORC, en virtud de la remisión que efectúa a aquel precepto, y colmar dichas lagunas con las exigencias que tanto el $\mathrm{TC}^{12}$, como el $\mathrm{TS}^{13}$ han requerido para aceptar la validez de las intervenciones telefónicas en el proceso penal, efectuando las necesarias adaptaciones derivadas del hecho de que dicha medida es acordada en un proceso de naturaleza civil como lo es el concursal.

En consecuencia, la medida de intervención telefónica en el proceso concursal ha de tener como finalidad exclusiva la obtención de información relevante para el interés del concurso, con garantía del secreto de los contenidos que sean ajenos al concurso, pudiendo recaer únicamente sobre los teléfonos de la persona del deudor o, si se tratare de una persona jurídica, de sus administradores o liquidadores, siempre y cuando existan indicios previos de los que inferir que dichos sujetos sustraen u ocultan información relevante al Juez del concurso o a la administración concursal y no meras sospechas o conjeturas.

Una vez acordada la intervención, el control ulterior de su práctica deberá aplicarse sobre tres extremos esenciales: $1^{\circ}$ ) El seguimiento de que, en efecto, se produce el cumplimiento estricto de lo autorizado, de modo que los encargados de la realización material de las interceptaciones vienen siempre obligados a facilitar una periódica, puntual y frecuente información al Juez del concurso del desarrollo y los resultados de las tareas que se les ha encomen-

${ }^{12}$ Cfr., entre otras, SSTC 259/2005, 165/2005, 167/2002, 14/2001, 236/1999, 49/1996.

13 Vid. entre otras, SSTS núms. 957/2005, de 18 de julio, 841/2005, de 28 de junio, 864/2005, de 22 de junio, 1489/2004, de 18 de diciembre, 999/2004, de 19 de diciembre, $322 / 2004$, de 12 de marzo, 343/2002, de 7 de marzo. 
dado, de acuerdo con lo dispuesto por el propio Juez en su resolución; $2^{\circ}$ ) La evitación de extralimitaciones en la ejecución de la diligencia acordada, tanto por exceso o prolongación innecesaria en la interceptación como por intromisión injustificada en otros ámbitos que no afecten al desarrollo del concurso o derechos de terceros ajenos a la investigación; y $3^{\circ}$ ) De modo muy especial, este control tendrá también como finalidad la evitación de cualquier clase de indefensión para el sometido a la intervención, de modo que al no haber tenido éste, como es lógico, conocimiento previo de la actuación sobre el secreto de sus comunicaciones, es el Juez el encargado, durante ese período, de tutelar debidamente todo lo relativo a la posibilidad de su ejercicio efectivo del derecho de defensa.

Singular importancia adquiere en el ámbito del concurso de acreedores la intervención de la correspondencia, como medida de indudable utilidad para la obtención de datos sobre cuestiones tan importantes para el fin del concurso como lo son: información bancaria, cartas comerciales, cartas de reclamación de deudas, comunicaciones con proveedores, comunicaciones con asesores fiscales, con la Hacienda Pública, con las Seguridad Social o con otras administraciones públicas.

Al igual que sucede con las telefónicas, la intervención de la correspondencia (cartas, paquetes postales, telegramas) ha de ser, por tanto, siempre proporcionada al fin perseguido, excepcional y nunca excesiva, tanto en su adopción como en su ejecución, y verdaderamente necesaria, más imprescindible que meramente conveniente u oportuna, para la consecución de los importantes objetivos que con ella se pretendan, esto es, la obtención de datos relevantes para el fin del concurso y, en concreto, de la documentación precisa para integrar la masa activa y pasiva del concurso, pues, tal y como señala CARRERAS MARAÑA ${ }^{14}$, en la integración y adecuada conformación de esas masas radica la esencia y el interés del concurso.

Asimismo, la resolución judicial que acuerde la intervención, que habrá de revestir la forma de Auto, deberá de hacer expresa indicación de la correspondencia que haya de ser intervenida, con designación de los remitentes de esa correspondencia (bancos, entidades de gestión financiera, administraciones públicas, asesorías fiscales, etc), a los que se cursarán los correspondientes mandamientos de retención y la indicación de dónde se debe entregar la correspondencia intervenida.

Debido a la ausencia en la LORC de previsión legal que regule la materialización de la intervención de las comunicaciones, con la finalidad de colmar dicha laguna creemos de aplicación lo dispuesto en los arts. 584-588 LECrim, preceptos que potencian, de un lado, la vigencia del principio de inmediación judicial y, de otro, el de contradicción.

${ }^{14}$ Cfr. CARRERAS MARAÑA, J.M., Efectos del concurso sobre los derechos fundamentales del concursado. Análisis del artículo primero de la Ley Orgánica 8/2003, de 9 de julio, op. cit., pág. 270. 
De conformidad con lo dispuesto en dichos preceptos, una vez que el Juez del concurso disponga íntegramente de la totalidad de los soportes originales, se procederá por dicho órgano judicial tanto a su apertura, como a la selección de la información que resulte de interés para el concurso, a cuyo acto deberán ser citados el deudor y, de modo especial, su Abogado defensor, así como la administración concursal. La trascripción en el acta de la correspondencia intervenida se realizará bajo la fe del Secretario, garantizándose el secreto de los contenidos que sean ajenos al concurso.

\section{LA ENTRADA Y REGISTRO EN EL DOMICILIO DEL DEUDOR}

Junto a la intervención de las comunicaciones, la LORC, en su artículo primero, también contempla la entrada en el domicilio del deudor y su registro como una de las medidas que puede adoptar el Juez del concurso.

El objeto material de esta medida lo constituye cualquier lugar cerrado en el que se ejercita o puede resultar afectado el derecho a la intimidad, a la vida familiar o a la privacidad del deudor como persona física, o de los administradores o liquidadores, en el caso de persona jurídica («domicilio común») ${ }^{15}$, así como los lugares en donde el derecho a la intimidad se proyecta sobre otros bienes constitucionales, tales como el secreto profesional ${ }^{16} \mathrm{o}$ la libertad de expresión ${ }^{17}$, cuya titularidad recae también sobre las personas jurídicas $\left(«\right.$ domicilios especiales») ${ }^{18}$.

$\mathrm{Al}$ igual que sucede con el resto de medidas contempladas en dicho precepto, la diligencia de entrada y registro, al incidir en el ámbito de un derecho fundamental, cual es el contenido en el art. 18.2 CE (inviolabilidad del domicilio), ha de estar sometida al principio de proporcionalidad.

Su adopción por el Juez del concurso ha de revestir, pues, carácter indispensable para obtener el fin perseguido, que, a diferencia de lo que sucede con la intervención de las comunicaciones, aparece concretado en el artículo primero, apartado $5^{\circ} \mathrm{LORC}$, cuando dispone que, a falta de consentimiento del concursado, la autorización judicial de entrada y registro habrá de basarse en la existencia de indicios racionales de existencia de documentos de interés para el procedimiento concursal, que no hayan sido aportados por el concursado.

La existencia previa de dichos indicios, que no meras sospechas o conjeturas, habrán de ser aportados por los propios acreedores personados en la

${ }^{15}$ Cfr. SSTC 189/2004, 22/2003, 10/2002, 283/2000, 8/2000, 94/1999, 126/1995, 50/1995.

${ }^{16} \mathrm{Vid}$. STC 37/1989 y STEDH de 16 de diciembre de 1992 Asunto Niemietz.

${ }^{17}$ SSTC $171 / 1997$ y $144 / 1987$.

${ }^{18}$ Sobre esta doble noción de domicilio, Vid. GIMENO SENDRA, V., Derecho Procesal Penal, Editorial Colex, 2004, pág. 382 y 385; CABEZUDO BAJO, M.J., La inviolabilidad del domicilio y el proceso penal, Iustel, 2004, pág. 106. 
causa como titulares de un interés legítimo en la eficacia del proceso y, especialmente, por la administración concursal.

En este sentido, el art. 45.2 LC dispone que «a solicitud de la administración concursal, el Juez acordará las medidas que estime necesarias para la efectividad de lo dispuesto en el apartado anterior», que establece la obligación del deudor de poner a disposición de la administración concursal los libros, documentos y registros relativos a los aspectos patrimoniales de su actividad patrimonial.

Ello no obstante, no basta con la existencia de dichos indicios de los que inferir que en el domicilio del concursado existen documentos de interés para el concurso, siendo también preciso, para dotar de legitimidad constitucional a la medida de entrada y registro, que sea necesaria u objetivamente justificada, de tal suerte que no ha de existir otra «alternativa menos gravosa» para el derecho fundamental que posibilite plenamente la consecución de dicho fin sin lesionar el derecho a la inviolabilidad del domicilio ${ }^{19}$.

Junto con la búsqueda de documentos que se presuma puedan hallarse en el domicilio del deudor y sean relevantes para el proceso concursal, la LORC también legitima la intromisión en el derecho a la intimidad personal y familiar del concursado cuando la entrada y registro sea necesaria para la adopción de cualquier otra (medida) procedente .

En principio, nada hay que objetar a la búsqueda de documentos que sean de interés para el concurso, pero, entender lícita la intromisión para adoptar otra medida procedente sin especificar cuál pueda ser, constituye una autorización que, en el ámbito del proceso civil, cabe considerar no sólo desproporcionada, sino contraria a la necesaria precisión que debe tener toda Ley de desarrollo de derechos fundamentales y, desde luego, concluir que debe entenderse prohibida la injerencia salvo para la búsqueda de documentos, única función expresa y autorizada ${ }^{20}$.

\section{LA OBLIGACIÓN DE RESIDENCIA Y EL ARRESTO DOMICI- LIARIO}

La última de las medidas restrictivas de derechos fundamentales contempladas en el artículo primero de la LO 8/2003 hace referencia al deber de residencia del deudor en la población de su domicilio y al arresto domicilia-

\footnotetext{
${ }^{19}$ Piénsese, a título de ejemplo, en la potestad que se concede al Tribunal, previa solicitud del ejecutante, para poder dirigirse a las entidades financieras, organismos y registros públicos, personas físicas y jurídicas que el ejecutante indique, con el fin de que hagan entrega de cuantos documentos y datos tengan en su poder y sean relevantes (arts. 590 y 591 LEC). Un comentario a dichos preceptos puede encontrarse en ORTELLS RAMOS, M., Proceso Civil Práctico (AA.VV., Director: Vicente Gimeno Sendra), Tomo VII, op . cit., págs. 237-252

${ }^{20}$ Vid. ASENCIO MELLADO, J.M., Ley Concursal, (AA.VV., Coordinadora: Esperanza Gallego Sánchez), Tomo I, op. cit., págs. 507 y 508.
} 
rio, que afectan al derecho a la libertad de residencia y circulación (art. 19 $\mathrm{CE}$ ), así como al derecho a la libertad (art. $17 \mathrm{CE}$ ), respectivamente.

En relación con tales medidas, el legislador se limita a señalar que el Juez podrá acordar «el deber de residencia del deudor persona natural en la población de su domicilio. Si el deudor incumpliera este deber o existieran razones fundadas para temer que pudiera incumplirlo, el juez podrá adoptar las medidas que considere necesarias, incluido el arresto domiciliario».

La redacción de dicho precepto presenta serias dudas de constitucionalidad, por cuanto no cumple con uno de los presupuestos de carácter común que ha de observarse en toda limitación de derechos fundamentales, cual es el principio de legalidad, ya que no efectúa concreción alguna de las circunstancias que han de concurrir para que el órgano judicial imponga al deudor la obligación de residir en un determinado lugar. En consecuencia, no reúne las condiciones mínimas suficientes requeridas por las exigencias de seguridad jurídica y certeza del derecho.

Asimismo, el arresto domiciliario del deudor se supedita al incumplimiento o al riesgo de que se incumpla el deber de residencia, sin referencia alguna a la finalidad pretendida por ambas medidas. En relación con dicha medida cautelar, la comparación entre los requerimientos dimanantes del art. 17 de nuestra Constitución, tal y como los ha delimitado la doctrina del TC, y las circunstancias bajo las que el precepto transcrito permiten acordar el arresto domiciliario, pone de manifiesto, «prima facie», que la Ley ni exige la presencia de un fin constitucionalmente legítimo para acordar tal medida, ni determina cuáles son los fines constitucionalmente legítimos que permiten acordarla ni, por lo tanto, exige que éstos se expresen en la resolución que la acuerda $^{21}$.

En todo caso, con ambas medidas de lo que se trata es de asegurar que el deudor concursado y los administradores o liquidadores de la persona jurídica concursada estarán permanente y fácilmente localizables por el Juzgado y por la administración concursal durante la tramitación del procedimiento y que, además, estarán cercanos a aquél y, en consecuencia, con posibilidad de comparecer rápidamente ante él ${ }^{22}$.

${ }^{21}$ Tal y como señaló el Pleno del TC en su Sentencia 47/2000, dicha insuficiencia legal bastaría para entender vulnerado el derecho a la libertad del deudor consagrado en el art. 17 CE.

${ }^{22}$ En este sentido, la STC 178/1985, de 19 de diciembre, había declarado que: «La necesidad de que el quebrado esté personalmente disponible para cuanto el proceso de quiebra demanda y por el tiempo indispensable ... es una causa legítima para limitar su libertad. Pero esta limitación ha de ser proporcionada al fin que la justifique. Cuando el arresto se convierte en carcelario, subordinado a la disponibilidad económica de una fianza, excede manifiestamente de esa proporcionalidad entre el objetivo y la medida adoptada. En este sentido, el arresto carcelario es incompatible con el art. 17.1 CE, pero no lo es la restricción de libertad que supone el arresto del quebrado en su propio domicilio por el tiempo indispensable para asegurar la finalidad del proceso de quiebra. 
Hubiera sido conveniente haber previsto expresamente la adopción de medidas intermedias entre el deber de residencia y la plena libertad ambulatoria, como podrían serlo la prohibición de abandonar el territorio nacional o comunitario y la retirada del pasaporte, medidas que, tanto por la falta de previsión específica en la LORC, como por la imposibilidad de aplicación analógica de la nueva regulación de la prisión provisional y, en concreto, del art. 530 LECrim., no podrán ser adoptadas por el Juez del concurso ${ }^{23}$.

Asimismo, y debido también a la suficiente precisión que debe tener toda Ley de desarrollo de derechos fundamentales, la única medida que el Juez puede adoptar en el caso de incumplimiento por el deudor del deber de residencia es, a mi entender, el arresto domiciliario, y ello aun cuando el artículo primero.1.2 $2^{\mathrm{a}}$ disponga que, ante dicha eventualidad, el «juez podrá adoptar las medidas que considere necesarias».

\section{ASPECTOS PROCESALES}

\section{Momento procesal para su adopción}

El momento procesal a partir del cual el Juez del concurso puede adoptar alguna de las medidas restrictivas de derechos fundamentales, anteriormente estudiadas, varía en función del tipo de concurso ante el que nos encontremos: tratándose de concurso necesario, podrán ser adoptadas desde el mismo instante de la admisión a trámite de la solicitud de declaración de concurso realizada por cualquiera de los acreedores; si, por el contrario, es el deudor quien solicita la declaración de concurso, habrá que esperar al momento de la declaración del concurso para que puedan ser acordadas, y ello con independencia de que rija un régimen de suspensión o de intervención de las facultades de administración y disposición del deudor sobre su patrimonio.

No existe un trámite concreto y preclusivo para la adopción de dichas medidas, por cuanto pueden adoptarse «en cualquier estado del procedimiento», siempre y cuando sean idóneas en la fase en que se adopten y resulten proporcionadas.

${ }^{23}$ Cfr. STC 169/2001; CARRERAS MARAÑA, J.M., Efectos del concurso sobre los derechos fundamentales del concursado. Análisis del artículo primero de la Ley Orgánica 8/2003, de 9 de julio, op. cit., pág. 277; ASENCIO MELLADO, J.A., Ley Concursal, (AA.VV., Coordinadora: Esperanza Gallego Sánchez), Tomo I, op. cit., págs. 512 y 513 . En contra, BERCOVITZ considera que, aun cuando el artículo 1.1.2 ${ }^{\circ}$ se refiere sólo a un deber de residencia, la medida puede extenderse a cualquier limitación de la libertad de circulación. BERCOVITZ RODRÍGUEZ CANO, R., Comentarios a la Ley Concursal (AA.VV., Director: Bercovitz Rodríguez Cano, R.), Vol. II, Tecnos, Madrid, 2004, pág. 2429. 


\section{Legitimación}

La legitimación activa para solicitar del Juez Mercantil alguna medida de las contempladas en la LORC también varía en función del momento concursal en que se efectúe dicha solicitud: si tiene lugar una vez admitida a trámite la solicitud de declaración de concurso necesario, podrán ser acordadas a instancia del legitimado para instarlo ${ }^{24}$; si, por el contrario, la petición sucede con posterioridad a la declaración de concurso, y tanto en los supuestos de concurso necesario como voluntario, la legitimación se amplia notablemente, pudiendo ser acordadas de oficio o a instancia de cualquier interesado.

Sin perjuicio de que resulte nuevamente censurable la poca concreción que efectúa el legislador en este sentido, considero que el inciso «cualquier interesado» ha de interpretarse en un sentido lo suficientemente amplio para entender incluido en su ámbito de aplicación no sólo a la administración concursal, cuya legitimación para solicitar del Juez del concurso cualquier medida, sea o no limitativa de derechos fundamentales, está fuera de toda duda (art. 45.2 LC), sino también a cualquier sujeto que acredite interés legítimo en la adopción de las medidas restrictivas de derechos fundamentales, interés que vendrá acreditado en la medida en que sus derechos o legítimas expectativas puedan depender de la normal tramitación del proceso concursal, a cuya finalidad coadyuvan tales medidas.

Tienen, pues, interés cualquier acreedor, aun cuando no sea de los que hayan solicitado la declaración de concurso, tanto concursal como de la masa activa, así como los responsables en cualquier grado de las deudas del patrimonio concursal: socios, administradores, liquidadores, cónyuge, los fiadores del deudor y el propio deudor persona jurídica ${ }^{25}$.

En cuanto a la legitimación del Ministerio Fiscal para solicitar la adopción de las medidas objeto de estudio, creemos que dicho órgano público la tendrá

${ }^{24}$ En tales casos de concurso necesario, los sujetos legitimados para instar el concurso son, con carácter general, los acreedores del deudor, excepción hecha del acreedor que, dentro de los seis meses anteriores a la presentación de la solicitud, hubiera adquirido el crédito por actos ínter vivos y a título singular, después de su vencimiento.

Junto a los acreedores del deudor común, están también legitimados: a) tratándose de una persona jurídica, los socios, miembros o integrantes que sean personalmente responsables, conforme a la legislación vigente, de las deudas de aquélla; b) los acreedores del deudor fallecido, los herederos de éste y el administrador de la herencia, si se trata de la declaración de concurso de la herencia no aceptada pura y simplemente; c) la Comisión Nacional del Mercado de Valores, para solicitar la declaración de concurso de las empresas de servicios de inversión, siempre que de los estados contables remitidos por las entidades, o de las comprobaciones realizadas por los servicios de la propia Comisión, resulte que se encuentran en estado de insolvencia (art. 76 bis de la Ley 24/1988, de 28 de julio, redactado por la D.F. $18^{\text {a }}$ de la LC) y d) el Consorcio de Compensación de Seguros, en el caso de concurso de una entidad aseguradora (art. 37.5 y 6 LOSSP).

${ }^{25}$ Cfr. BERCOVITZ RODRÍGUEZ CANO, R., Comentarios a la Ley Concursal, (AA.VV.), op. cit., pág. 2420. 
en dos supuestos: de un lado, cuando inste la declaración de concurso en representación de algunas de las personas cuya defensa le venga legalmente atribuida y, de otro, cuando se decrete la apertura de la sección sexta de calificación del concurso y precise de alguna de tales medidas restrictivas en orden a emitir el dictamen a que se refiere el art. 169 LC, en el que habrá de pronunciarse sobre la calificación del concurso, como fortuito o culpable, determinando también, en este último caso, la identidad de las personas que resulten afectadas por la calificación.

La legitimación pasiva la ostenta, para la totalidad de las medidas, tanto el deudor persona natural, como los administradores o liquidadores, si se tratare del concurso de una persona jurídica y, para las restricciones relacionadas con la intervención de las comunicaciones, así como, en determinados supuestos, con la entrada y registro del domicilio también la persona jurídica deudora; no en cambio el deber de residencia, ni el arresto domiciliario que, por su propia naturaleza y función, tan sólo son predicables de las personas físicas.

Como se ha señalado, tratándose del concurso de una persona jurídica, el artículo primero, apartado 2 LORC admite la posibilidad de que el Juez pueda adoptar alguna de las medidas contempladas en dicho texto respecto de todos o algunos de los administradores o liquidadores tanto actuales, como de los que lo hubieran sido en los dos años anteriores a contar desde la fecha de solicitud de declaración de concurso.

Dicho precepto exige efectuar algunas matizaciones con el fin de resolver algunos interrogantes que se suscitan en relación con su ámbito de aplicación.

En primer lugar, en relación con el dies a quo para el cómputo de los dos años, surge la duda de si ha de computarse desde el Auto de declaración de concurso o si, por el contrario, es el momento de la presentación de la solicitud el que ha de tenerse en consideración. A mi entender, la dicción de la Ley es lo suficientemente clara para considerar el momento de la presentación de la solicitud como el elemento temporal que haya de tenerse en cuenta para el cómputo del plazo de los dos años anteriores a los efectos de determinar los administradores o liquidadores que, a pesar de haber cesado en el cargo, puedan ser sujetos pasivos de medidas limitativas por haber ostentado dichas funciones y disponer de información trascendente para el proceso concursal, lo que exigirá una especial motivación.

Admitido lo anterior, y habida cuenta de que no se establece distinción alguna, creemos de aplicación lo dispuesto en dicho precepto tanto a los administradores o liquidadores de derecho, como de hecho ${ }^{26}$, esto es, a los que, sin

${ }^{26}$ En este sentido, señala BERCOVITZ: «Cierto que, tratándose de un supuesto de limitación de derechos fundamentales, debe aplicarse una interpretación restrictiva. Pero, por encima de ese criterio, debe predominar una interpretación sistemática y finalista, de acuerdo con la cual carecería de sentido extender la responsabilidad a los administradores y liquidadores de hecho en los términos en que lo hace la Ley concursal (vgr. arts. 48.3, 93.2.2 $\mathrm{y}$ 172.3 LC), y, sin embargo, excluirlas de la aplicación de estas medidas, cuya finalidad en úl- 
ocupar formalmente el cargo, de hecho controlan y gobiernan la sociedad, sustituyendo a los administradores o ejerciendo sobre ellos una influencia decisiva, gestionando y representando sin superior jerárquico real.

Mayores problemas plantea la resolución de si resulta o no posible la limitación de los derechos fundamentales de los representantes legales del concursado, cuando éste fuera un menor de edad o incapacitado.

Un sector de la doctrina entiende, efectuando una interpretación lógica y finalista del precepto, que no existe inconveniente alguno para entender que tales representantes legales puedan ser también sujetos pasivos de medidas limitativas en los mismos supuestos y dentro del plazo de los dos años previsto legalmente para los administradores y liquidadores de la persona jurídica, por cuanto la referencia legal a éstos últimos obedece a un descuido del legislador, que parece haber tenido en cuenta únicamente el caso paradigmático de actuación de sujeto (persona jurídica) por medio de otro (persona física), sin haberse percatado de que hay otros sujetos (menores o incapacitados) que también precisan actuar por medio de representante, quien puede obstaculizar la tramitación del procedimiento ocultando documentos o fugándose, exactamente igual que los administradores o liquidadores del deudor persona jurídica.

Ello no obstante, no es menos cierto que las normas que establezcan limitaciones de derechos, y más aún de derechos fundamentales, tienen que ser interpretadas restrictivamente, por lo que la aplicación analógica de esta norma, por muy lógica y razonable que sea, a unos sujetos no contemplados expresamente, y, en este caso, la LORC nada prevé sobre los representantes legales del deudor cuando éste sea una persona natural, resulta de dudosa constitucionalidad.

\section{Procedimiento y recursos}

La tramitación procesal, previa a la adopción de las medidas restrictivas de derechos fundamentales, es muy sencilla, ya que se limita a la preceptiva audiencia del MF, a quien, como es sabido, le corresponde velar por el respeto de los derechos fundamentales y libertades públicas (art. 3.3 EOMF), y a su adopción mediante resolución motivada, que ha de revestir la forma de auto, en la que se ha de efectuar necesariamente el juicio de ponderación entre el derecho o derechos fundamentales afectados y los intereses que tal afectación trata de proteger.

tima instancia está estrechamente relacionada con dicha responsabilidad, puesto que con ellas se pretende evitar perjuicios al patrimonio concursal y, consecuentemente, perjuicio a sus acreedores». Vid. BERCOVITZ RODRÍGUEZ CANO, R., Comentarios a la Ley Concursal, (AA.VV.), op. cit.., pág. 2420. 
Contra los autos que acuerden las medidas, cabe recurso de apelación en el plazo de cinco días ante la Audiencia Provincial, que se tramitará con carácter preferente, pero que no tendrá efecto suspensivo. $\mathrm{Si}$, por el contrario, el Auto es desestimatorio, no se admite recurso alguno.

\section{CONCLUSIONES}

I. La regulación contenida en la LORC en materia de limitación de derechos fundamentales del deudor concursado supone una mejora notable en relación con la prevista en la LEC de 1881 y C.Com. de 1829, no sólo porque se haya unificado en único texto legal toda la regulación, sino muy especialmente porque se ha suprimido el efecto automático y represivo que presentaban tales medidas en la normativa anterior, teniendo ahora como único objetivo asegurar el cumplimiento de los fines del concurso.

II. Ello no obstante, la LORC adolece de vaguedad e indeterminación en aspectos esenciales que hace que los requisitos de certeza y seguridad, inherentes al principio de legalidad y exigidos por la jurisprudencia del TEDH para la adopción de medidas limitativas de derechos fundamentales, no se hallen en ocasiones cumplidos, lo que plantea serias dudas en cuanto a su constitucionalidad.

La remisión expresa que se efectúa en materia de intervención de comunicaciones telefónicas a la LECrim., la previsión legal de adopción de la medida de entrada y registro cuando sea necesaria «para la adopción de cualquier otra» o de que el Juez pueda acordar «las medidas que considere necesarias», en caso de que el deudor incumpliera el deber de residencia, unido a la vaga e imprecisa regulación que se efectúa en cuanto a los criterios de limitación en la duración de las medidas, constituyen claros ejemplos de dicha falta de concreción.

III. La descuidada regulación que se efectúa de determinados aspectos formales compromete la eficacia real de la Ley, haciendo muy difícil el cumplimiento de su finalidad genuina y legítima, esto es, garantizar el normal desarrollo del procedimiento concursal. En este aspecto, resulta inexplicable la omisión que efectúa el legislador de los representantes legales del concursado (p.ej. un menor o un incapaz), así como de los administradores de hecho de la persona jurídica como sujetos destinatarios de las medidas.

IV. El legislador en su afán de suprimir los efectos represivos del concurso y establecer únicamente los necesarios para el buen fin del mismo, dada la unánime crítica que había suscitado la regulación anterior en el aspecto referente al arresto del quebrado, parece haber querido facultar al órgano judicial para adoptar medidas menos gravosas, olvidando, sin embargo, que, en una materia que afecta a derechos fundamentales, cualquier medida limitativa debe estar expresamente prevista en la Ley y, en este punto, la falta de previsión de medidas intermedias entre el deber de residencia y arresto domiciliario comporta la imposibilidad de adoptarlas. 
V. Por todo ello, y debido al gran margen de libertad que otorga la LORC al Juez de lo Mercantil, la labor del MF y la AP será especialmente importante en cuanto al control coetáneo y a posteriori de las resoluciones dictadas en materia de restricción de derechos fundamentales por dicho órgano concursal. 